\title{
Increased serum levels of SIO0AI, ZAG, and adiponectin in cachectic patients with COPD
}

This article was published in the following Dove Press journal:

International Journal of COPD

\section{Amin Mokari-Yamchi' \\ Akbar Sharifi² \\ Sorayya Kheirouri'}

'Department of Community Nutrition, Faculty of Nutrition and Food Science, Tabriz University of Medical Sciences, Tabriz, Iran; ${ }^{2}$ Tuberculosis and Lung Research Center, Tabriz University of Medical Sciences, Tabriz, Iran
Correspondence: Sorayya Kheirouri Department of Community Nutrition, Faculty of Nutrition and Food Science, Tabriz University of Medical Sciences, Tabriz, Iran

Tel +98935552 I56I

Fax +98 4I 42257858

Email kheirouris@tbzmed.ac.ir
Background: COPD is a common irreversible obstructive airway disease. S100A1, ZAG, and adiponectin are important regulators of energy metabolism and body weight. Therefore, the aim of this study was to assess resting metabolic rate (RMR) and its association with serum levels of S100A1, ZAG, and adiponectin in cachectic and noncachectic COPD patients.

Patients and methods: Ninety men with COPD, aged 40-70 years, were enrolled in the study. Patients were divided into the following two groups based on the unintentional weight loss of .7.5\% in previous 6 months: noncachectic $(n=45)$ and cachectic $(n=45)$. The groups were matched based on age and body mass index (BMI). RMR was measured by indirect calorimetry method. Anthropometric indices and body composition were also measured. Serum levels of S100A1, ZAG, and adiponectin were measured by ELISA.

Results: Cachectic patients had significantly higher RMR than controls $(P<0.001)$. Serum levels of ZAG, S100A1, and adiponectin were significantly higher in the cachexia group $(P<0.0001)$. RMR was not significantly associated with S100A1, ZAG, and adiponectin levels. However, weight loss of patients was significantly associated with serum levels of ZAG and adiponectin (both, $\beta=0.22, P=0.03$ ). Strong and positive association were found between the serum levels of S100A1 and ZAG ( $\beta=0.88, P<0.0001)$, S100A1 and adiponectin $(\beta=0.86, P<0.0001)$, and also $Z A G$ and adiponectin $(\beta=0.83, P<0.0001)$.

Conclusion: The potential role of these factors in the wasting process is considerable. Also, the association between serum levels of S100A1, ZAG, and adiponectin represents that these three proteins are probably related to specific functions.

Keywords: COPD, cachexia, RMR, S100A1, ZAG, adiponectin

\section{Introduction}

COPD is an irreversible obstructive airway disease and has obvious systemic inflammatory consequences in other organs. ${ }^{1}$ The major symptoms of COPD are dyspnea, chronic cough, and increased airway mucus production. ${ }^{2}$ The WHO has estimated that 65 million people in the world suffer from moderate-to-severe COPD and, in 2015, about 3 million people died because of COPD. ${ }^{3}$ Also, the prevalence and burden of COPD are increasing due to the changing in age structure of the world's population and also the continued exposure to different risk factors. ${ }^{4}$ People suffer from COPD are at risk for serious complications including heart failure, pneumonia, depression, and cachexia.,

With the disease progression, up to $25 \%$ of patients develop cachexia that subsequently leads to a $50 \%$ reduction in the average survival rate in these patients. ${ }^{7}$ The exact mechanism underlying cachexia is unknown, but it is suggested that dysregulation of energy metabolism and proinflammatory cytokines may play a role in the pathogenesis of cachexia. $^{8}$ 
Resting metabolic rate (RMR) accounts for the largest portion of total daily energy expenditure in individuals with limited physical activity. Previously, it has been shown that the condition of COPD is associated with increased RMR. ${ }^{9}$ In addition, elevated RMR was observed in underweight COPD patients. ${ }^{10}$ Recently, there has been a growing interest in identifying biomarkers, which were thought to play an important role in RMR and in lean/fat body mass regulation.

$\mathrm{S} 100 \mathrm{~A} 1$ is one of the exchange factor (EF)-hand family of $\mathrm{Ca}(2+)$-binding proteins that is mainly expressed in cardiac and skeletal muscles. Evidence shows that S100A1 could act as a regulator of sarcoplasmic reticulum $\mathrm{Ca} 2+$ handling of skeletal muscle and mitochondrial function. ${ }^{11}$ A more recent investigation has suggested that dysregulation of intracellular calcium homeostasis might play an important role in the induction of cachexia. Moreover, genetic association studies revealed a link between S100A1 and RMR. ${ }^{12,13}$ Although it has been suggested that S100A1 acts as a calcium sensor in adipose tissue, which could play a role in the regulation of weight, ${ }^{14}$ the association between serum levels of S100A1 with RMR is unclear.

Zinc alpha 2-glycoprotein (ZAG) is a soluble single-chain polypeptide that is present in serum and other body fluids and is secreted by several human tissues, including liver, breast, lung, and adipocytes. ${ }^{15}$ ZAG stimulates lipid loss by adipocytes and is known as the lipid mobilizing factor that may involve in the loss of adipose tissue and weight. ${ }^{16}$ Administration of ZAG to mice induces reduction in body fat and increases serum-free fatty acid levels, by activating hormone-sensitive lipase. In catabolic conditions such as cancer cachexia, enhanced expression and secretion of ZAG has been observed. ${ }^{17}$

Adiponectin is a hormone mostly produced in adipose tissue that has both anti-inflammatory and antiobesity effects. ${ }^{18}$ Previous studies showed that adiponectin plays a role in energy homeostasis by the activation of AMP kinase and enhancing insulin sensitivity. Elevated circulatory levels of adiponectin have been demonstrated in COPD patients, particularly in underweight subjects. ${ }^{10,19}$

Thus, in this study, we hypothesized that S100A1 and ZAG may contribute to RMR and accordingly in the pathogenesis of cachexia. To the best of our knowledge, the role of S100A1 and ZAG has not been investigated in COPD patients. Moreover, the association between serum levels of S100A1 with RMR, ZAG, adiponectin, and weight loss are also unknown. Therefore, we designed our research to primarily investigate differences in RMR as well as serum levels of S100A1, ZAG, and adiponectin in body mass index (BMI)-matched cachectic and noncachectic COPD patients.
Second, we aimed to find possible relationships between S100A1 with RMR, ZAG, adiponectin, and weight loss in COPD patients.

\section{Methods}

\section{Study design and participants}

In this study, we enrolled 90 clinically stable outpatient males, aged 40-70 years. COPD diagnosis was based on $\mathrm{FEV}_{1} /$ $\mathrm{FVC}<70 \%$, which is in accordance with the GOLD recommendations. ${ }^{20}$ Exclusion criteria included cardiac failure and severe endocrine, hepatic, or renal disorders. Patients were divided into the following two groups based on the unintentional weight loss of $>7.5 \%$ in previous 6 months: noncachectic $(n=45)$ and cachectic $(n=45)$. The two groups were matched for age (within 5-year age groups as 40-44, 45-49, 50-54, 55-59, 60-64, and 65-70 years) and BMI (within five BMI groups as $<18.49,18.5-24.9,25-29.9,30-34.9$, and $35-39.9 \mathrm{~kg} / \mathrm{m}^{2}$ ). The study was reviewed and approved by the ethics committee (no IR.TBZMED.REC.1395.779) of Tabriz University of Medical Sciences, and written informed consent was obtained from all participants.

\section{Pulmonary function tests}

Pulmonary function including FVC, $\mathrm{FEV}_{1}$ (\% predicted), and $\mathrm{FEV}_{1} / \mathrm{FVC}$ ratio was measured using Spirolab III (Medical International Research, Rome, Italy) and according to the guidelines of the American Thoracic Society. ${ }^{21}$ The test was performed while the participants rested for 15 minutes before measurement. A powerful forced expiration was done after maximum forced inhalation without using a nose clip.

\section{Anthropometric and body composition measurements}

Height and weight of the participants were measured to the nearest $0.1 \mathrm{~kg}$ and $0.5 \mathrm{~cm}$, respectively, with standard, calibrated scales. Previous baseline weights of participants were obtained from their medical reports. BMI was calculated as weight divided by height squared $\left(\mathrm{kg} / \mathrm{m}^{2}\right)$. Waist and arm circumference were measured using an ordinary tape with a nearest $0.5 \mathrm{~cm}$. Body composition analyses including fatfree mass (FFM), fat $\%$, and total body water (TBW) were measured using the bioelectrical impedance analysis (BIA) device (BC-418; Tanita Corp., Tokyo, Japan). The FFM index (FFMI) $\left(\mathrm{kg} / \mathrm{m}^{2}\right)$ was calculated as the ratio of FFM to height in meters squared.

\section{Measurement of RMR}

RMR was measured by indirect calorimetry (Fitmate MED; COSMED, Rome, Italy) according to the oxygen 
consumption and production of carbon dioxide and converted to energy expenditure using formulae. Fitmate is a desktop device designed to measure oxygen consumption and energy expenditure during rest and exercise. It uses a facemask that was placed over the participant's face in a seated and relaxed position and was attached to turbine flow meter to measure ventilation and a galvanic fuel cell oxygen sensor for analyzing the proportion of oxygen in expiration gases. The participants were instructed to rest in the supine position. The test was performed after 10-12 hours of overnight fasting. Subjects abstained from exercise for 24 hours before the test. Participants also refrained from smoking and caffeine for 12 hours before the study.

\section{Assessment of dietary intake and appetite}

Dietary intake assessment was done using the 24-hour recall method. The individuals were interviewed about their food and beverage consumption during the previous day. VAS method was used to assess hunger and eating habits. The VAS was used to evaluate appetite by using a $10 \mathrm{~cm}$ analog scale from poor appetite to good appetite. ${ }^{22}$

\section{Physical activity assessment}

The Persian long-form version of the International Physical Activity Questionnaire (IPAQ) was used to assess the average total physical activity during the previous 7 days. ${ }^{23}$ The total physical activity scores were calculated in metabolic equivalent of task (MET) minutes/week and classified into walking, moderate, and vigorous activities according to IPAQ guidelines.

\section{Biochemical analysis}

Blood samples were obtained from the patients, and the serum was separated by centrifugation at $4^{\circ} \mathrm{C}$ and stored at $-70^{\circ} \mathrm{C}$. Human ELISA kits (Eastbiopharm, Hangzhou, China) were used to measure serum levels of S100A1 (cat no CK-E90946), ZAG (cat no CK-E91945), and adiponectin (cat no CK-E10871). The absorbances were read at $450 \mathrm{~nm}$ using an Automatic ELISA Plate Reader (BioTek Instruments, Winooski, VT, USA).

\section{Statistical analyses}

All the analyses were performed using SPSS 19.0 (IBM Corporation, Armonk, NY, USA). The Kolmogorov-Smirnov test was used to assess variables' distribution normality. Categorical variables were compared with chi-squared test. Comparisons of quantitative variables between two groups were made using the independent samples' $t$-test (normal distribution). In addition, the analysis of covariance was performed to adjust for confounders. Associations between variables were assessed using linear regression. $P$-value $<0.05$ was considered statistically significant.

\section{Results}

The general characteristics of the studied subjects are shown in Table 1. Age, time elapsed from diagnosis, calorie intake, and satiety score were similar in the two groups. The amount of $\mathrm{FVC}, \mathrm{FEV}_{1}$, and $\mathrm{FEV}_{1} / \mathrm{FVC}$ ratio in cachectic patients was lower than that in noncachectic patients. Also, cachectic group showed lower physical activity level.

Mean BMI level of the subjects was not statistically different between the two groups. In cachectic and noncachectic groups, the documented weight loss was $6.44 \pm 2.83 \mathrm{~kg}$

Table I Characteristics of patients included in the study

\begin{tabular}{|c|c|c|c|}
\hline Variables & $\begin{array}{l}\text { COPD without cachexia } \\
(n=45)\end{array}$ & $\begin{array}{l}\text { COPD with cachexia } \\
(n=45)\end{array}$ & $P$-value \\
\hline Age (years) & $58.5 \pm 7.5$ & $60.1 \pm 7.2$ & $0.31 *$ \\
\hline Time elapsed from diagnosis (years) & $5.2 \pm 3.7$ & $5.7 \pm 3.9$ & $0.58 *$ \\
\hline Calorie intake (kcal) & $\mathrm{I}, 596.6 \pm 40 \mathrm{I} .3$ & $\mathrm{I}, 493.48 \pm 58 \mathrm{I}$ & $0.12^{*}$ \\
\hline Satiety score & $51.7 \pm 12.1$ & $56.88 \pm 15.3$ & $0.08^{*}$ \\
\hline FVC (\% predicted) & $70.8 \pm 15.3$ & $59.8 \pm 18.5$ & $0.003^{*}$ \\
\hline $\mathrm{FEV}_{\text {, }}(\%$ predicted $)$ & $56.1 \pm 8$ & $44.8 \pm 17.3$ & $0.00 I^{*}$ \\
\hline $\mathrm{FEV}_{1} / \mathrm{FVC}$ ratio & $55.7 \pm 6.6$ & $50.3 \pm 9.5$ & $0.003^{*}$ \\
\hline Physical activity & & & $0.002^{* *}$ \\
\hline Low & $22(48.8)$ & $36(80)$ & \\
\hline Moderate & $23(5 \mathrm{l} .1)$ & $9(20)$ & \\
\hline Drug therapy & $44(97.7)$ & $44(97.7)$ & I** \\
\hline Salbutamol ipratropium bromide & $37(82.2)$ & $40(88.8)$ & $0.42 * *$ \\
\hline Prednisolone & $24(53.3)$ & $21(46.6)$ & $0.38 * *$ \\
\hline Salmeterol + fluticasone & $34(75.5)$ & $32(7 I .1)$ & $0.66 * *$ \\
\hline Azithromycin & $16(35.5)$ & $14(3 \mid .1)$ & $0.82 * *$ \\
\hline
\end{tabular}

Notes: Quantitative and qualitative variables are represented as mean \pm SD and frequency $(\%)$, respectively. $* P$-values are reported based on independent sample's $t$-test. **P-values are reported based on chi-squared test. 
Table 2 Body composition and anthropometric parameters

\begin{tabular}{l|l|l|l}
\hline \multirow{2}{*}{ Variables } & \multicolumn{2}{l}{ The study groups } & \multirow{2}{*}{-value* $^{*}$} \\
\cline { 2 - 3 } & $\begin{array}{l}\text { COPD without cachexia } \\
(\mathbf{n}=\mathbf{4 5})\end{array}$ & $\begin{array}{l}\text { COPD with cachexia } \\
(\mathbf{n}=\mathbf{4 5})\end{array}$ & \\
\hline Height $(\mathrm{cm})$ & $170.37 \pm 5.69$ & $168.62 \pm 9.62$ & 0.29 \\
Current weight $(\mathrm{kg})$ & $67.97 \pm 9.83$ & $65.74 \pm 9$ & 0.26 \\
Former weight $(\mathrm{kg})$ & $68.84 \pm 10.35$ & $72.08 \pm 10.08$ & 0.13 \\
BMl $\left(\mathrm{kg} / \mathrm{m}^{2}\right)$ & $23.35 \pm 2.88$ & $22.74 \pm 2.29$ & 0.26 \\
Waist circumference $(\mathrm{cm})$ & $90.04 \pm 9.39$ & $89.96 \pm 9.35$ & 0.96 \\
Arm circumference $(\mathrm{cm})$ & $27.77 \pm 2.61$ & $29.34 \pm 6.83$ & 0.15 \\
Percentage of body fat & $18.98 \pm 5.37$ & $18.89 \pm 4.10$ & 0.92 \\
Fat-free mass $(\mathrm{kg})$ & $54.67 \pm 5.41$ & $53.40 \pm 6.87$ & 0.33 \\
Fat-free mass index $\left(\mathrm{kg} / \mathrm{m}^{2}\right)$ & $18.84 \pm 1.51$ & $19 \pm 3.26$ & 0.76 \\
Total body water $(\mathrm{kg})$ & $42.79 \pm 5.09$ & $42.06 \pm 6.83$ & 0.56 \\
\hline
\end{tabular}

Notes: Data are expressed as mean $\pm \mathrm{SD}$. ${ }^{*} P$-values are reported based on independent samples' $t$-test.

Abbreviation: BMI, body mass index.

$(8.81 \% \pm 3.58 \%)$ and $0.86 \pm 2.48 \mathrm{~kg}(1.13 \% \pm 3.29 \%)$, respectively. According to Table 2, body composition and anthropometric parameters' comparison between groups showed no significant differences.

The mean RMR in cachectic and noncachectic subjects was $1,815.17 \pm 350.41$ and $1,479.49 \pm 316.77 \mathrm{kcal}$, respectively. As shown in Figure 1, the differences between groups were statistically significant.

Cachectic patients had significantly higher serum S100A1, ZAG, and adiponectin levels. These differences persisted even after adjustment for physical activity and RMR (Figure 1).
A

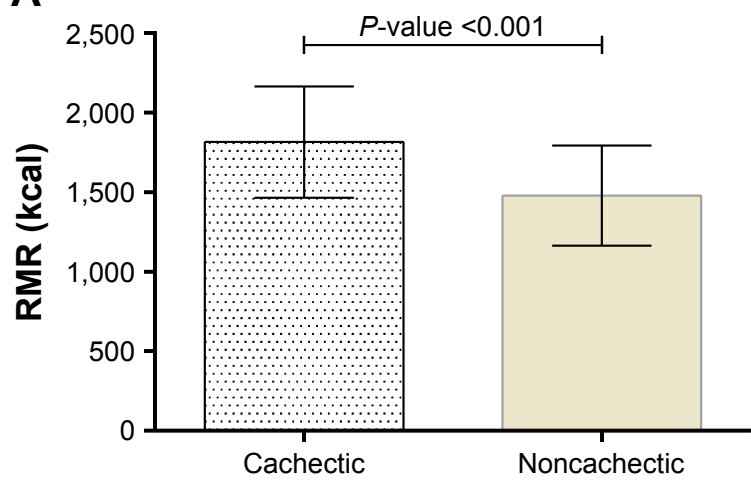

C

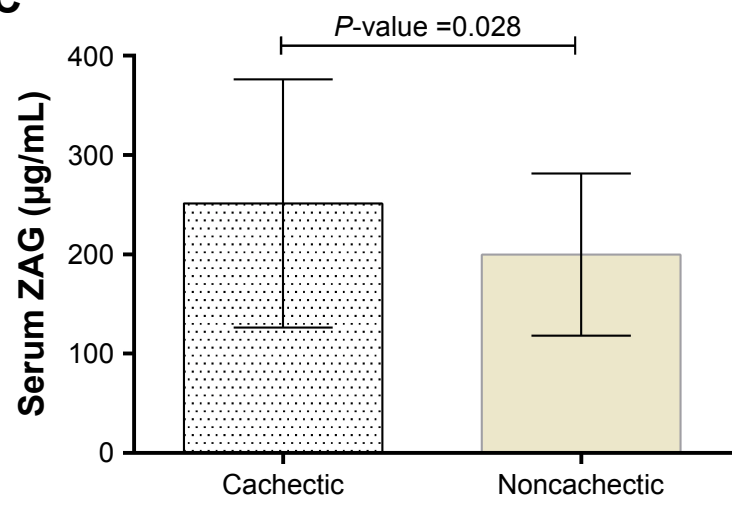

B

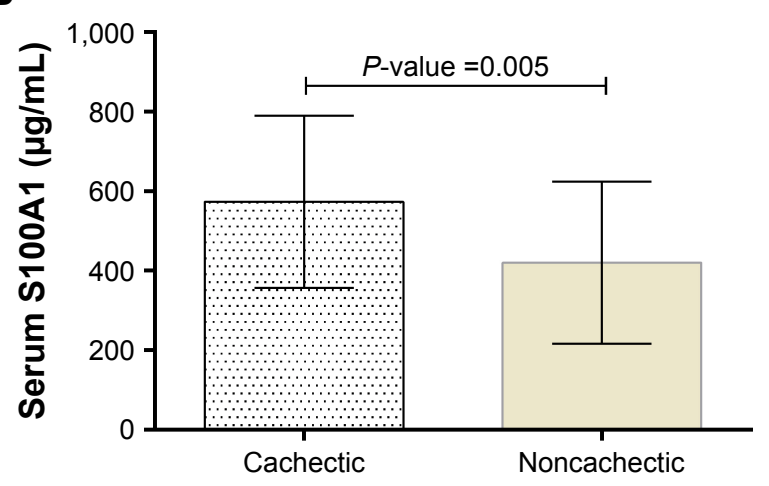

D

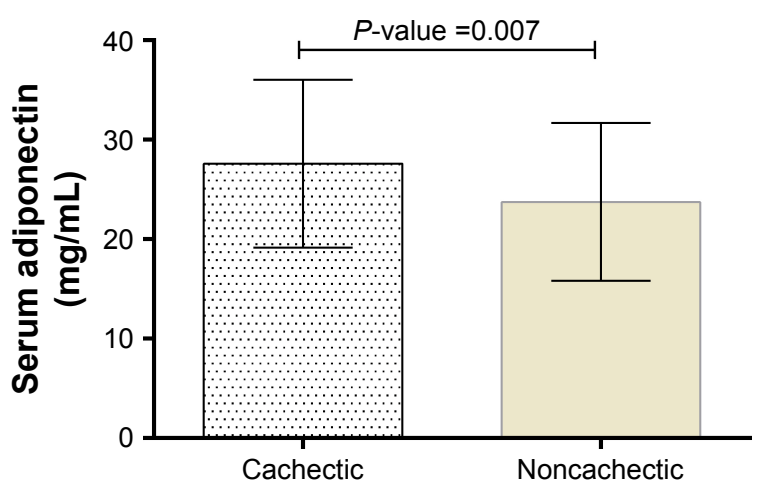

Figure I RMR (A) and serum levels of SI00AI (B), ZAG (C), and adiponectin (D) in cachectic and noncachectic groups.

Notes: Data are presented as mean \pm SD. P-values are reported based on ANCOVA after controlling the physical activity and RMR.

Abbreviations: RMR, resting metabolic rate; ZAG, zinc alpha 2-glycoprotein. 
Table 3 Associations between SI00AI, ZAG, and adiponectin with RMR, anthropometric measurements, body composition, and weight loss

\begin{tabular}{|c|c|c|c|c|c|c|}
\hline \multirow[t]{2}{*}{ Variables } & \multicolumn{2}{|c|}{ SIOOAI } & \multicolumn{2}{|l|}{ ZAG } & \multicolumn{2}{|c|}{ Adiponectin } \\
\hline & $\beta$ & $P$-value & $\beta$ & $P$-value & $\beta$ & $P$-value \\
\hline RMR & 0.02 & 0.84 & 0.084 & 0.41 & -0.062 & 0.55 \\
\hline BMI & 0.046 & 0.66 & 0.08 & 0.45 & -0.042 & 0.69 \\
\hline Waist circumference & 0.13 & 0.22 & 0.13 & 0.19 & -0.025 & 0.81 \\
\hline Arm circumference & 0.1 & 0.31 & 0.051 & 0.63 & 0.062 & 0.56 \\
\hline Percentage of body fat & 0.11 & 0.30 & 0.14 & 0.18 & 0.048 & 0.65 \\
\hline Fat-free mass & 0.039 & 0.71 & 0.092 & 0.38 & -0.006 & 0.95 \\
\hline Weight loss & 0.19 & 0.06 & 0.22 & 0.03 & 0.22 & 0.03 \\
\hline
\end{tabular}

Note: Data analysis was done by linear regression.

Abbreviations: BMI, body mass index; RMR, resting metabolic rate; ZAG, zinc alpha 2-glycoprotein.

As shown in Table 3, ZAG and adiponectin were associated positively with weight loss. No association was found between RMR and the blood biomarkers. Also, anthropometric and body composition parameters did not show significant association with the blood biomarkers.

Strong and positive association was observed between S100A1 and ZAG $(\beta=0.88)$, adiponectin and $Z A G(\beta=0.86)$, and adiponectin and S100A1 $(\beta=0.86)$ (Table 4).

\section{Discussion}

In the present study, cachectic patients had higher RMR than noncachectic patients. Previous findings demonstrated elevated resting energy expenditure in COPD and also among underweight cachectic patients. ${ }^{9,10,24}$ Brúsik et al examined 44 patients with COPD and found that REE was significantly higher in underweight compared to normal and obese patients. ${ }^{10}$ The need for energy in COPD patients increases due to infection and work of breathing. Breathing with healthy lungs requires $36-72 \mathrm{kcal} /$ day; in patients with COPD, this amount increases by 10 -fold. ${ }^{25}$ Other associated factors that may well contribute to elevated RMR in cachectic patients include impairment in the muscle's oxidative phenotype and increased reliance on glycolytic metabolism. ${ }^{26}$

In this study, we reported our novel finding that the cachectic patients had higher S100A1 concentration than noncachectic patients. To our knowledge, no previous study has evaluated serum S100A1 levels in cachexia and its correlation with RMR. S100A1 interacts with mitochondrial $\alpha$ and $\beta$ chains of F1-ATPase in a Ca2+-dependent manner. ${ }^{11}$ According to the previous studies on animal models and human-specific genotypes, S100A1-F1-ATPase complex plays a key role in ATP production and energy hemostasis. An animal model study showed that mice with S100A1 knockout have reduced ATP synthase activity in cardiomyocytes. ${ }^{27}$ Tran et al showed that the level of $\beta$-F1-ATPase expression in the muscles of obese people was lower than lean subjects. ${ }^{28}$ However, the results of the present study did not show any association between serum levels of S100A1 and RMR. Our data provide the basis for speculation that the elevation of serum S100A1 levels may be linked to the pathogenesis of cachexia in COPD patients. However, the exact mechanism is not clear yet!

Our present study demonstrated a clear difference in ZAG levels between cachectic and noncachectic patients with no difference in fat mass. ZAG has been considered as an adipokine involved in lipid metabolism, and various studies have shown that ZAG expression and concentration were associated with increased lipolysis in tissue wasting conditions such as cancer cachexia. ${ }^{17,29}$ In patients with COPD, Balaz et al $(2015)^{30}$ observed sevenfold higher expression of ZAG

Table 4 Associations between SI00AI, ZAG, and adiponectin

\begin{tabular}{|c|c|c|c|c|c|c|}
\hline \multirow[t]{2}{*}{ Variables } & \multicolumn{2}{|c|}{ All patients $(n=90)$} & \multicolumn{2}{|c|}{ COPD without cachexia $(n=45)$} & \multicolumn{2}{|c|}{ COPD and cachexia $(n=45)$} \\
\hline & $\beta$ & $P$-value & $\beta$ & $P$-value & $\beta$ & $P$-value \\
\hline SIO0AI-ZAG & 0.88 & $<0.0001$ & 0.86 & $<0.0001$ & 0.88 & $<0.0001$ \\
\hline Adiponectin-ZAG & 0.83 & $<0.0001$ & 0.80 & $<0.0001$ & 0.85 & $<0.0001$ \\
\hline Adiponectin-SI00AI & 0.86 & $<0.000 \mathrm{I}$ & 0.86 & $<0.0001$ & 0.86 & $<0.0001$ \\
\hline
\end{tabular}

Note: Data analysis was done by linear regression.

Abbreviation: ZAG, zinc alpha 2-glycoprotein. 
in cachectic than in obese patients. The exact mechanism of action of ZAG on the weight loss is not known yet. ZAG may increase lipolysis through elevated hormone-sensitive lipase activity and stimulation of $\beta$-adrenoreceptors. In addition, ZAG inhibits the activity of several key enzymes in the lipogenesis pathway that may contribute to the development of cachexia. ${ }^{31,32}$

Our results showed that serum adiponectin levels were increased in cachectic patients. Similar to our study, in 2009, Araújo et al evaluated serum adiponectin levels in cardiac cachexia. Cachexia was defined as unintentional weight loss of more than $7 / 5 \%$ of the previous baseline weight. They observed that cachectic patients had significantly higher adiponectin levels than controls. ${ }^{33}$ Adiponectin through activation of adenosine monophosphate activated kinase increases glucose uptake and fatty acid oxidation in peripheral tissues. ${ }^{34}$ A study on mice showed decreased body weight after the administration of adiponectin without inhibiting food intake and change in serum glucose and lipid levels. ${ }^{35}$

The other novel findings of the current study are the strong positive association between serum levels of adiponectin with ZAG and S100A1. We also found such an association between S100A1 and ZAG serum levels, which was also observed in our previous study among metabolic syndrome patients. Moreover, as we suggested in our previous study, production or release of S100A1 and ZAG might be related to each other mechanistically. ${ }^{36}$

The relationship between adiponectin and ZAG has been demonstrated in genetic studies. Marrades et al, ${ }^{37}$ in 2008 , revealed positive correlation between ZAG gene expression of subcutaneous abdominal adipose tissue and serum adiponectin. Two years later, Mracek et $\mathrm{al}^{38}$ showed that a $1.5 \mu \mathrm{g} / \mathrm{mL}$ dose injection of recombinant ZAG in adipocytes during differentiation increased adiponectin release 1.5- to 2 -fold. Thus, we speculate that one of the possible roles of ZAG might be regulation of the adiponectin.

To our knowledge, there is no other study in the literature demonstrating the relationship between adiponectin and S100A1 serum levels. However, data from separate studies suggested that the two peptides may act in a same direction. Several studies identified the impact of S100A1 on $\mathrm{Ca} 2+$ homeostasis through an enhanced $\mathrm{Ca} 2+$ release and augmented SR Ca2+ reuptake. ${ }^{39,40}$ In contrast, adiponectin induces $\mathrm{Ca} 2+$ influx by adiponectin receptor $1 .{ }^{41}$ As calcium deregulation has been found in skeletal muscle of cachectic patients, ${ }^{42}$ it is probable that these two proteins might be related functionally.

\section{Conclusion}

We demonstrated that RMR and serum levels of S100A1, $\mathrm{ZAG}$, and adiponectin are independently increased in COPD patients with cachexia compared with COPD controls matched by age and BMI. Therefore, the potential role of these factors in the pathogenesis of cachexia is considerable. Strong positive association between serum levels of S100A1, ZAG, and adiponectin increase the possibility of their pathophysiological functions in cachectic patients. Further studies are required to confirm this association and reveal the exact pathophysiological mechanisms.

\section{Acknowledgments}

We thank the patients for participating in the studies. We also thank Research Vice-Chancellor and Student Research Committee of Tabriz University of Medical Sciences for their financial support.

\section{Disclosure}

The authors report no conflicts of interest in this work.

\section{References}

1. Vestbo J, Hurd SS, Agustí AG, et al. Global strategy for the diagnosis, management, and prevention of chronic obstructive pulmonary disease: GOLD executive summary. Am J Respir Crit Care Med. 2013;187(4): 347-365.

2. Ko FW, Cheung NK, Rainer TH, Lum C, Wong I, Hui DS. Comprehensive care programme for patients with chronic obstructive pulmonary disease: a randomised controlled trial. Thorax. 2017;72(2):122-128.

3. World Health Organization Global Burden of Disease Study [homepage on the Internet]. Available from: http://www.who.int/respiratory/copd/ burden/en/. Accessed November 26, 2017.

4. Kim YS. Definition and epidemiology of COPD. In: Lee SD, editor. COPD. Berlin: Springer; 2017:3-7.

5. Huertas A, Palange P. COPD: a multifactorial systemic disease. Ther Adv Respir Dis. 2011;5(3):217-224.

6. Sin DD, Anthonisen NR, Soriano JB, Agusti AG. Mortality in COPD: Role of comorbidities. Eur Respir J. 2006;28(6):1245-1257.

7. Wagner PD. Possible mechanisms underlying the development of cachexia in COPD. Eur Respir J. 2008;31(3):492-501.

8. Morley JE, Thomas DR, Wilson MM. Cachexia: pathophysiology and clinical relevance. Am J Clin Nutr. 2006;83(4):735-743.

9. Creutzberg EC, Schols AM, Bothmer-Quaedvlieg FC, Wouters EF. Prevalence of an elevated resting energy expenditure in patients with chronic obstructive pulmonary disease in relation to body composition and lung function. Eur J Clin Nutr. 1998;52(6):396-401.

10. Brúsik M, Ukropec J, Joppa P, et al. Circulatory and adipose tissue leptin and adiponectin in relationship to resting energy expenditure in patients with chronic obstructive pulmonary disease. Physiol Res. 2012;61(5):469-480.

11. Völkers M, Rohde D, Goodman C, Most P. S100A1: A Regulator of Striated Muscle Sarcoplasmic Reticulum Ca2+ handling, sarcomeric, and mitochondrial function. J Biomed Biotechnol. 2010;2010:178614.

12. Marenholz I, Heizmann CW, Fritz G. S100 proteins in mouse and man: from evolution to function and pathology (including an update of the nomenclature). Biochem Biophys Res Commun. 2004;322(4):1111-1122. 
13. Jacobson P, Rankinen T, Tremblay A, Pérusse L, Chagnon YC, Bouchard C. Resting metabolic rate and respiratory quotient: results from a genome-wide scan in the Quebec Family Study. Am J Clin Nutr. 2006;84(6):1527-1533.

14. Olofsson L. Molecular mechanisms in obesity-associated metabolic disease. Inst of Medicine. Dept of Molecular and Clinical Medicine. 2007.

15. McDermott L, Jadoon A, Cunningham P. ZAG and a potential role in systemic lipid homeostasis: examining the evidence from in vitro human studies and patients with chronic illness. Clin Lipidol. 2012;7(4): 409-417.

16. Cabassi A, Tedeschi S. Zinc- $\alpha 2$-glycoprotein as a marker of fat catabolism in humans. Curr Opin Clin Nutr Metab Care. 2013;16(3): 267-271.

17. Mracek T, Stephens NA, Gao D, et al. Enhanced ZAG production by subcutaneous adipose tissue is linked to weight loss in gastrointestinal cancer patients. Br J Cancer. 2011;104(3):441-447.

18. Ohashi K, Yuasa D, Shibata R, Murohara T, Ouchi N. Adiponectin as a target in obesity-related inflammatory state. Endocr Metab Immune Disord Drug Targets. 2015;15(2):145-150.

19. Tomoda K, Yoshikawa M, Itoh T, et al. Elevated circulating plasma adiponectin in underweight patients with COPD. Chest. 2007;132(1): 135-140.

20. Pauwels RA, Buist AS, Calverley PM, Jenkins CR, Hurd SS; GOLD Scientific Committee. Global strategy for the diagnosis, management, and prevention of chronic obstructive pulmonary disease. NHLBI/WHO Global Initiative for Chronic Obstructive Lung Disease (GOLD) Workshop summary. Am J Respir Crit Care Med. 2001;163(5):1256-1276.

21. Association MSotAL. Standardization of Spirometry, 1994 Update. American Thoracic Society. American journal of respiratory and critical care medicine. 152(3):1107-1136.

22. Flint A, Raben A, Blundell JE, Astrup A. Reproducibility, power and validity of visual analogue scales in assessment of appetite sensations in single test meal studies. Int J Obes Relat Metab Disord. 2000;24(1): 38-48.

23. Vasheghani-Farahani A, Tahmasbi M, Asheri H, Ashraf H, Nedjat S, Kordi R. The Persian, last 7-day, long form of the International Physical Activity Questionnaire: translation and validation study. Asian J Sports Med. 2011;2(2):106-116.

24. Schols AM, Soeters PB, Mostert R, Saris WH, Wouters EF. Energy balance in chronic obstructive pulmonary disease. Am Rev Respir Dis. 1991;143(6):1248-1252.

25. Mahan L, Kathleen L, Janice L. Raymond. Krause's food \& the nutrition care process-e-book. Elsevier Health Sciences. 2016:689.

26. Remels AH, Gosker HR, Langen RC, Schols AM. The mechanisms of cachexia underlying muscle dysfunction in COPD. J Appl Physiol (1985). 2013;114(9):1253-1262.

27. Boerries M, Most P, Gledhill JR, et al. Ca2+-dependent interaction of S100A1 with F1-ATPase leads to an increased ATP content in cardiomyocytes. Mol Cell Biol. 2007;27(12):4365-4373.
28. Tran L, Hanavan PD, Campbell LE, et al. Prolonged Exposure of Primary Human Muscle Cells to Plasma Fatty Acids Associated with Obese Phenotype Induces Persistent Suppression of Muscle Mitochondrial ATP Synthase $\beta$ Subunit. PLoS One. 2016;11(8):e0160057.

29. Felix K, Fakelman F, Hartmann D, et al. Identification of serum proteins involved in pancreatic cancer cachexia. Life Sci. 2011;88(5-6): 218-225.

30. Balaz M, Ukropcova B, Kurdiova T, et al. Adipokine zinc- $\alpha 2$ glycoprotein regulated by growth hormone and linked to insulin sensitivity. Obesity (Silver Spring). 2015;23(2):322-328.

31. Xiao X, Li H, Qi X, et al. Zinc alpha2 glycoprotein alleviates palmitic acid-induced intracellular lipid accumulation in hepatocytes. Mol Cell Endocrinol. 2017;439:155-164.

32. Russell ST, Tisdale MJ. Mechanism of attenuation of skeletal muscle atrophy by zinc-alpha2-glycoprotein. Endocrinology. 2010;151(10) 4696-4704.

33. Araújo JP, Lourenço P, Rocha-Gonçalves F, Ferreira A, Bettencourt P. Adiponectin is increased in cardiac cachexia irrespective of body mass index. Eur J Heart Fail. 2009;11(6):567-572.

34. Yamauchi T, Kamon J, Minokoshi Y, et al. Adiponectin stimulates glucose utilization and fatty-acid oxidation by activating AMP-activated protein kinase. Nat Med. 2002;8(11):1288-1295.

35. Qi Y, Takahashi N, Hileman SM, et al. Adiponectin acts in the brain to decrease body weight. Nat Med. 2004;10(5):524-529.

36. Ebrahimi E, Kheirouri S, Alizadeh M. Down-regulation of S100A1 protein in patients with metabolic syndrome and its association with zinc- $\alpha 2$-glycoprotein. Scott Med J. 2017;62(3):88-95.

37. Marrades MP, Martínez JA, Moreno-Aliaga MJ. ZAG, a lipid mobilizing adipokine, is downregulated in human obesity. $J$ Physiol Biochem 2008;64(1):61-66.

38. Mracek T, Ding Q, Tzanavari T, et al. The adipokine zinc-alpha2glycoprotein (ZAG) is downregulated with fat mass expansion in obesity. Clin Endocrinol (Oxf). 2010;72(3):334-341.

39. Most $\mathrm{P}$, Bernotat J, Ehlermann $\mathrm{P}$, et al. S100A1: a regulator of myocardial contractility. Proc Natl Acad Sci U S A. 2001;98(24):13889-13894.

40. Most P, Remppis A, Pleger ST, et al. Transgenic overexpression of the $\mathrm{Ca} 2+$-binding protein S100A1 in the heart leads to increased in vivo myocardial contractile performance. J Biol Chem. 2003;278(36): 33809-33817.

41. Iwabu M, Yamauchi T, Okada-Iwabu M, et al. Adiponectin and AdipoR1 regulate PGC-1alpha and mitochondria by $\mathrm{Ca}(2+)$ and AMPK/SIRT1 Nature. 2010;464(7293):1313-1319.

42. Conte E, Camerino GM, Mele A, et al. Growth hormone secretagogues prevent dysregulation of skeletal muscle calcium homeostasis in a rat model of cisplatin-induced cachexia. J Cachexia Sarcopenia Muscle. 2017;8(3):386-404.
International Journal of COPD

\section{Publish your work in this journal}

The International Journal of COPD is an international, peer-reviewed journal of therapeutics and pharmacology focusing on concise rapid reporting of clinical studies and reviews in COPD. Special focus is given to the pathophysiological processes underlying the disease, intervention programs, patient focused education, and self management protocols.

\section{Dovepress}

This journal is indexed on PubMed Central, MedLine and CAS. The manuscript management system is completely online and includes a very quick and fair peer-review system, which is all easy to use. Visi http://www.dovepress.com/testimonials.php to read real quotes from published authors. 